\title{
An Experimental Insight into the Smoldering-Flaming Transition Phenomenon
}

\author{
Poorva Shrivastava, Chakshu Baweja, Herambraj Nalawade, A. Vinoth Kumar, \\ Vikram Ramanan, and Vinayak Malhotra
}

Department of Aerospace Engineering, SRM University, Chennai 603203, India

Correspondence should be addressed to Vinayak Malhotra; vinn99@gmail.com

Received 21 September 2016; Revised 25 October 2016; Accepted 1 November 2016; Published 1 January 2017

Academic Editor: Jun Han

Copyright ( 2017 Poorva Shrivastava et al. This is an open access article distributed under the Creative Commons Attribution License, which permits unrestricted use, distribution, and reproduction in any medium, provided the original work is properly cited.

\begin{abstract}
Transitional phenomena of smoldering combustion over thin solid fuels are investigated. An experimental setup was upraised and implications of both smoldering and flaming external heat sources are estimated. Incense sticks were used as potential fuel and external smoldering heat source along with a fixed candle flame. The role of key controlling parameters, namely, separation distance and number of external heat sources in horizontal and vertical direction, was extensively examined. The surfacing issues of enclosure effect and the external heat sources orientation are addressed. The study primarily aims at understanding the feasibility and spontaneity of transition owing to external heat sources (both flaming and smoldering). Forward heat transfer significantly deviates qualitatively and quantitatively with varying separation distance in both directions. Number of external heat sources intensifies the transition phenomenon in smoldering combustion. With practical considerations, external heat sources arrangement and orientation have substantial effect on the combustion process.
\end{abstract}

\section{Introduction}

Smoldering is flameless form of combustion phenomenon, deriving heat from heterogeneous reactions occurring on the surface of a solid fuel (Figure 1). Smoldering combustion can be initiated by weak sources of heat and yields a high conversion of fuel to toxic products per unit mass smoldered (particularly CO and heavy molecules). One of the important attributes of smoldering is that it is difficult to detect and extinguish and it can abruptly transit to flaming. One of the major lessons learned is that it is impossible to eliminate all ignition sources, so fire inhibition is achieved through use of fire resistant materials and prevention of external resources to eliminate excessive spread. It is of interest both as a fundamental combustion problem and as a practical fire hazard. In spite of its weak-combustion characteristics, it is a significant fire threat. Hence, fundamental understanding of smoldering spread over solids is important for practical, scientific, and engineering applications. Smoldering combustion is broadly studied and defined according to the direction in which the smolder reaction propagates relative to the oxidizer flow (Figure 2). In opposed smoldering, the reaction front propagates in the direction opposite to the oxidizer flow, and in forward smoldering, the front propagates in the same direction. These two configurations are distinguished by the roles played by the transport mechanisms and chemical reactions. In forward propagation, the fresh oxidizer flows through the char and reacts at the ignition zone and then the oxidizer-depleted flow goes through the virgin fuel. This configuration favors that the oxidation reactions occur at the rear of the ignition zone and pyrolysis at the front. In opposed propagation, the fresh oxidizer flows through the virgin fuel and reacts at the smolder zone favoring that both the oxidation and the pyrolysis reactions occur at approximately the same location. The study of smoldering combustion phenomena is primarily driven by the need to have better fire safety, by means of enhanced understanding of the mechanisms that control the spread and extinction. Present work focuses on opposed mode of combustion, namely, reverse smoldering and opposed flow flame spreading. 


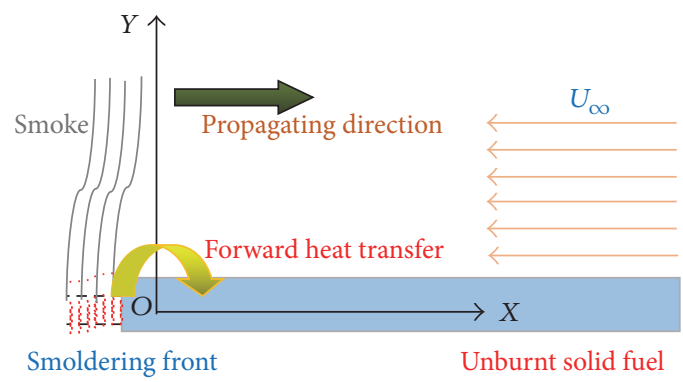

FIGURE 1: Schematic of smoldering combustion and forward heat transfer.

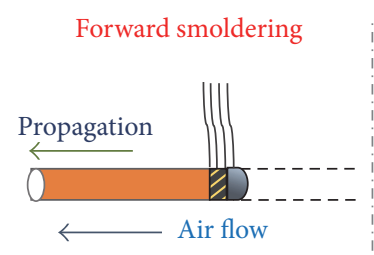

(a)

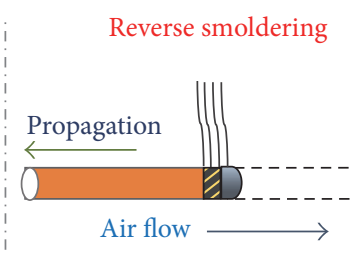

(b)

FIGURE 2: Schematics of (a) forward smoldering and (b) reverse smoldering over thin solid fuel.

In the recent past, Leach et al. [1] studied the kinetic and fuel property effect on forward smoldering combustion from a one-dimensional transient model. The effects of the inlet gas velocity, kinetic frequency factors, inlet oxygen concentration, and fuel properties such as specific heat, density, conductivity, and pore diameter were studied. Krause and Schmidt [2] presented a mathematical model which allows one to treat the combined phenomena of heat, mass, and species transfer by diffusion as they occur within smoldering fires in accumulations of dust or other solid bulk materials. Bar-Ilana et al. [3] figured out the transition from forward smoldering to flaming combustion using the small polyurethane foam samples. Aldushin et al. [4] tried to investigate the transitional combustion phenomenon from smoldering to flaming in forward smoldering configuration from a theoretical framework by considering a constant wave to explore the transition zone. Rein et al. [5] developed a one-dimensional computational model of smoldering combustion. The heterogeneous chemistry was modelled with a 5-step mechanism, so the model was able to predict qualitatively and quantitatively the smoldering behavior, reproducing the most important features of the process. The fact that it was possible to predict the experimental observations in both reverse and forward propagation with a single model was a significant improvement in the development of numerical models of smoldering combustion. Aldushin et al. [6] initiated further study with a different setup for reverse heat transfer and tried to check feasibility. Rein [7] attempted to synthesize a comprehensive view of smoldering combustion bringing together contributions from diverse scientific disciplines. Dodd et al. [8] developed a 2D numerical model with eight-step reduced reaction mechanism to study the spontaneous transition from smoldering to flaming combustion. The investigation was carried out on forward smoldering with externally applied heat flux. Three reactions were predicted to play important role in prediction of transition to flaming.

In light of above-mentioned works, an important feature to note is that almost all of smoldering spread studies are carried out with a single fuel to understand the spreading mechanism. However, in most of practical situations spreading front interacts with nearby surfaces or potential heat sources (flaming and smoldering). These interactions can have major implications which can influence the regression rates. Interaction of smoldering spread with an external heat source is likely to alter the spreading behavior from that of a single fuel. External heat source releases heat from the heated surface and can enhance heat feedback to the pilot unburnt fuel. This heat feedback is likely to increase pyrolysis of fuel resulting stronger ignition front. Appreciable work had been done but complexity of the problem has prevented a complete understanding due to nonlinear interaction between flow, heat, and mass transfer. Therefore, a systematic study is needed to understand mechanisms controlling the heat transfer behavior of the smoldering combustion. Hereby, in this work, the effect of external heat source on transition of combustion modes, namely, smoldering to flaming and vice versa with respective spread behavior, is investigated experimentally. The increase or decrease of regression rate can have significant effects and applications in engineering background. The objectives of the present study may be summarized as follows:

(I) To study the implications of the external heat sources (flaming and smoldering) on smoldering combustion

(II) To investigate the transitional combustion behavior of flame to smoldering combustion and vice versa 


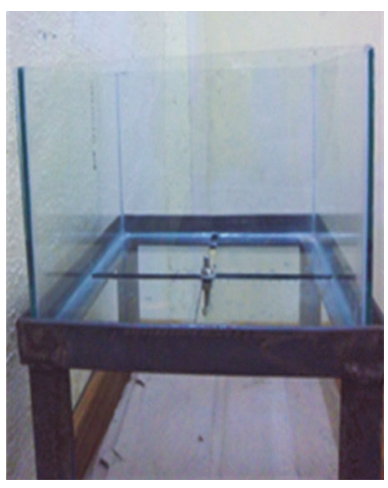

(a)

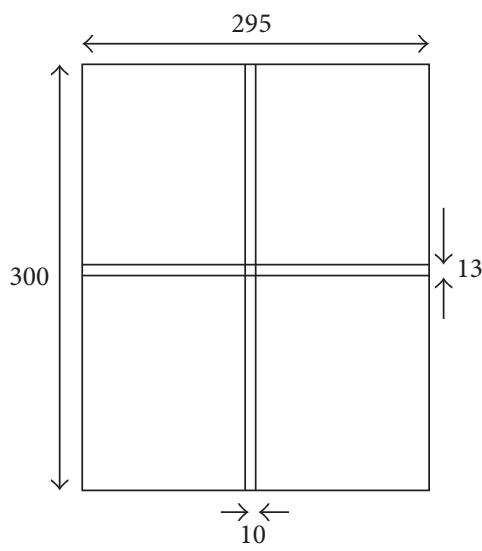

(b)

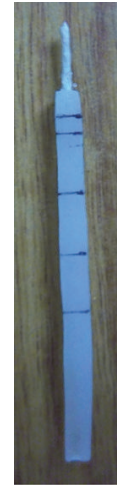

(c)

FIGURE 3: Experimental setup: (a) side view and (b) schematic (all dimensions are in mm); (c) marked candle (external flaming source).

(III) To investigate the role of key controlling parameters, namely, number of external sources, separation distance, configurations symmetry, and enclosure on smoldering spread

\section{Experimental Setup and Solution Methodology}

A simple experimental apparatus was upraised for the present study. The apparatus comprises (a) rectangular glass enclosure (Figure 3) with top face open and base with four plus shaped open slits, (b) iron stand to support the enclosure at height from ground, (c) iron stand made of bolt and nut, (d) incense sticks as potential smoldering fuel, and (e) external heat sources, namely, smoldering (same incense sticks) and flaming (candle) for the conducting experimental simulations. The solid fuel assembly comprised dried incense sticks in $4.8 \mathrm{~cm} \times 0.20 \mathrm{~cm}$ specification. The composition of incense sticks is sawdust (30\%), charcoal (30\%), and cow dung (38$39.5 \%)$ and incense chemical $(<1.5 \%)$. The flaming heat source (candle) comprised paraffin wax candle stick $(30 \mathrm{~mm} \times 4 \mathrm{~mm}$ $\times 4 \mathrm{~mm}$ ) (Figure $3(\mathrm{c})$ ). The fuel sticks were marked in two parts; namely, opening $6 \mathrm{~mm}$ marking was provided on fuel stick for combustion stabilization and at two regular intervals of $10 \mathrm{~mm}$ to tack the ignition front propagation with time. Figure 4 shows the experimentation process. Smoldering fuel specimen strips are made to ensure uniform burning across the width of fuel as the front propagates along the length of fuel specimen. It is worth noting that, for all the configurations, candle flame was fixed at center and all smoldering external heat sources were placed symmetrically equidistant with respect to the candle flame. Ignition was done at the apex of the fuel sticks for all configurations using a kerosene lighter (please see Figure 4(c)). The candle wick is ignited once the spread rate of incense sticks(s) stabilized and at a particular location for all the configurations. The regression rate is very sensitive to the gas and the surface temperatures which are a part of solution procedure. Proper care was undertaken to remove the moisture which can affect ignition and front spread rate. The experiments were systematically carried out in a quiescent room under normal gravity conditions. In order to facilitate uniformity, every experiment was carried out within a range of 5 minutes to bring room atmosphere back to normalcy. Stopwatch was used to measure the split times across the markers. Entire experimentation process was digitally video-graphed to obtain precision in prediction of the propagating front (please see Figure 4(d)). It is important to note that the results represent repeatability ( 3 times) of the readings and the average repeated value was accounted. The ensemble-time averaged regression rate $r$ is given as

$$
r=\frac{l_{s}}{t_{\mathrm{av}}},
$$

where " $l_{s}$ " is the standard length of fuel taken (here, $1 \mathrm{~cm}$ ) and " $t_{\mathrm{av}}$ " is the average time taken for all three marked distances.

From classical theory of ignition spread, assuming unity width of fuel the regression rate $(r)$ is defined by energy balance as

$$
r=\frac{\int q_{\text {net }}}{\rho_{s} \tau_{s} c_{s}\left(T_{\text {Surface }}-T_{\infty}\right)},
$$

where $\int q_{\text {net }}$ is net integrated heat transfer rate, $c_{s}$ is solidphase specific heat, $\tau_{s}$ is solid fuel thickness, $\rho_{s}$ is solid fuel density, $T_{\text {Surface }}$ is smoldering temperature, and $T_{\text {Ambient }}$ is ambient temperature.

\section{Results}

Experimental simulations were carried out in purely natural convective atmosphere with $21 \%$ oxygen concentration. According to classical heat transfer theory over thin solid fuels, the propagating front spreads by heat feedback (forward heat transfer) from the burning to the unburnt solid fuel upstream. The heat feedback content will be reflected in increase or decrease in regression rates (refer to (2)). Initiation of smoldering instigates buoyant convective flow and formation of localized velocity and temperature fields on 


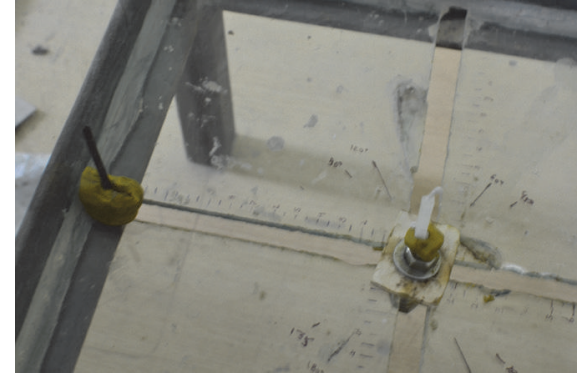

(a)

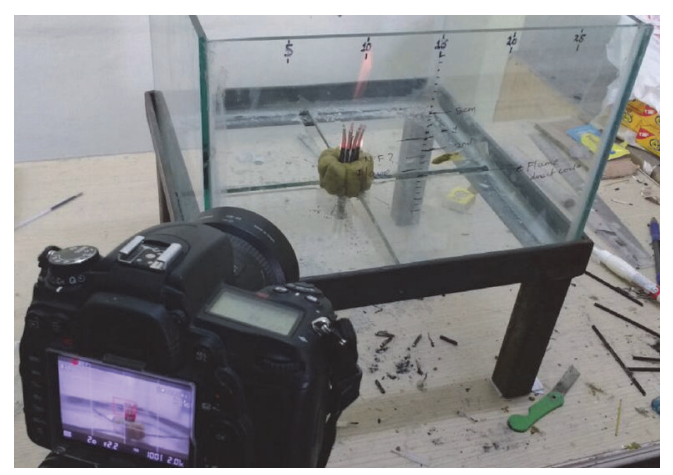

(d)

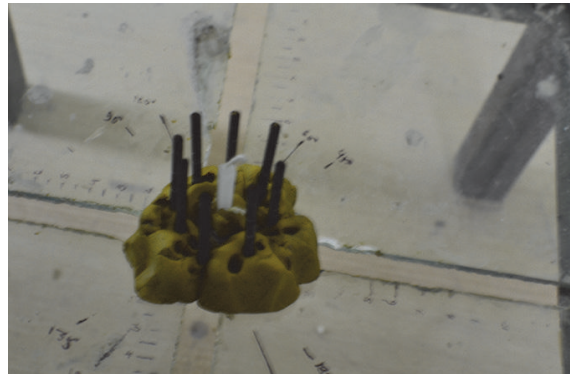

(b)

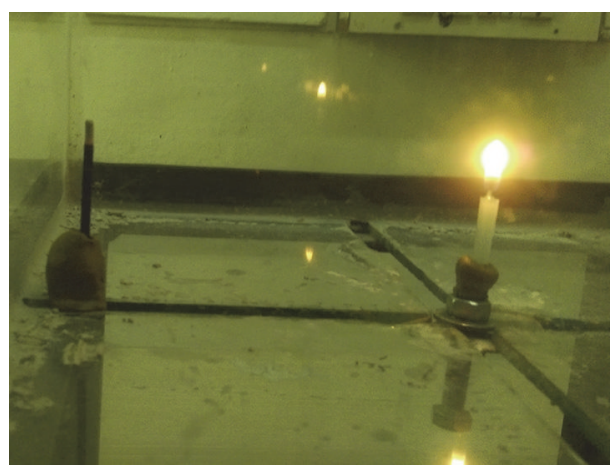

(e)

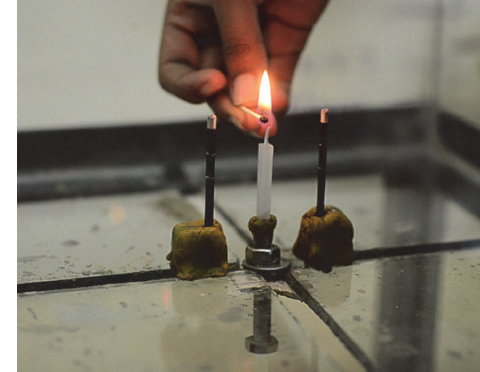

(c)

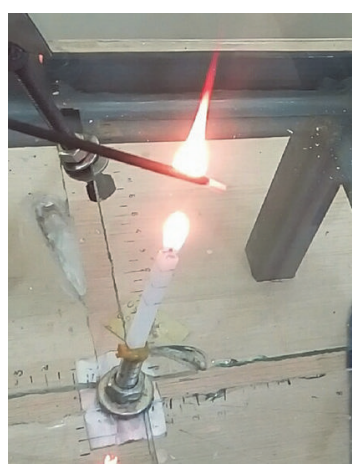

(f)

FIGURE 4: Pictorial view of experimental setup with (a) single-fuel configuration, (b) eight-fuel configuration, (c) ignition initiation, (d) video-graphed experimentation, (e) lateral direction smoldering, and (f) longitudinal direction smoldering.

the fuel surface. The presence of external heat sources (both smoldering and flaming) is anticipated to alter the cumulative heat transfer to the unburnt fuel. The altered heat transfer over a period of time may initiate combustion transitions at different levels, namely, unburnt fuel to smoldering, smoldering to flaming if increased, and flaming to smoldering and smoldering to extinction if reduced by substantial amount. The study intends to explore the feasibility and spontaneity of these transitions along with the extent and critical limits defining them. The smoldering transition phenomenon is investigated in aid of key controlling variables, namely, external heat source separation distance (in horizontal and vertical direction), number of incense sticks (external heat source), enclosure effect, and the orientation.

First, we look at the effect of the external heat source separation distance on smoldering combustion. To understand the effect, the separation distance with respect to the candle flame is divided into three specified regions, namely, wide-spaced $(>10 \mathrm{~cm})$, intermediately spaced $(2.5-$ $7.5 \mathrm{~cm})$, and narrow-spaced region $(<2.5 \mathrm{~cm})$, respectively. These regions are specified based on the relative proportion of the separation distance to the half width of the enclosure. Figure 5 shows the regression rate variation with separation distance of the external heat sources for distinct fuel-source configurations (single, two, three, and four) in comparison to the regression rate of a single incense without external thermal assistance. The regression rate for single incense stick in the absence of heat source (both smoldering and flaming) is lower than the regression rate(s) for all other parameters.
The pilot fuel regresses at $0.0534 \mathrm{~mm} / \mathrm{s}$ and is used as benchmark value for comparison. Looking at the plot one can note that as the separation distance for different configurations is reduced, a gradual and monotonic rise in regression rates is noted. This effect is seen across all configurations. The regression rates show insensitiveness in the widely spaced region whereas marginal effect is noted in the intermediately spaced configurations. Number of external heat sources modulates the effect as for four-stick configuration $\sim 9 \%$ rise in regression rate is noted at $3.5 \mathrm{~cm}$ followed by the same rise at $10 \mathrm{~cm}$. Small number of external sources (here, <3) exhibits near range statics to the one without external thermal assistance. The far field region is at a distance that is greater than the extent of natural convection induced by the heat sources. The heat transfer to the incense stick(s) from the candle is minimal, when they are placed far apart and the regression rates are very close to the "no heat source" values. Interestingly, at location of $7.5 \mathrm{~cm}$, all configurations merge to same value implying nonsignificant effect of external heat sources. The transitional combustion is established primarily in the nearfield zone for varying separation distance and configurations. With reduction of separation distance in near field zone for different configurations, drastic rise in regression rates is noted. At selected location of $0.50 \mathrm{~cm}$, single-fuel configuration reports $53 \%$ rise in regression rate whereas two-fuel configuration details $56 \%$ increase. It is interesting to note that the drastic rise drops in three-fuel configuration to $46 \%$. Maximum rise in regression rate is noted for four-fuel configuration with about $414 \%$ rise. As 


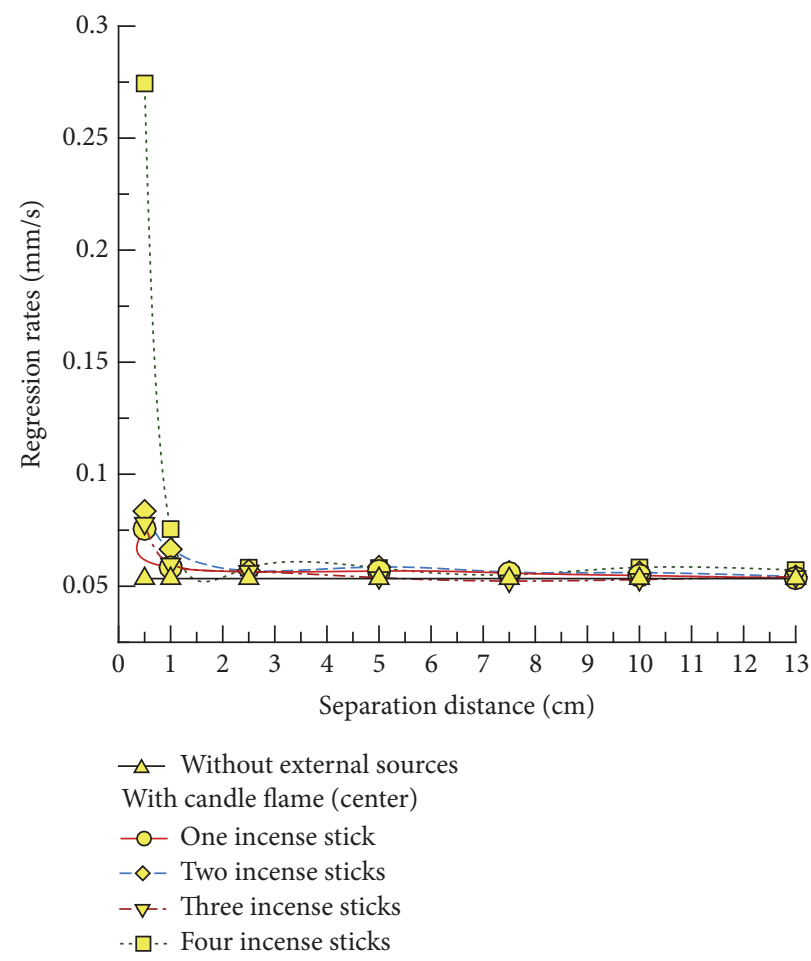

FIGURE 5: Effect of varying external heat sources and pilot fuel configuration on smoldering regression rates.

regression rate primarily depends upon heat transfer to the unburnt pilot fuel, the account of unprecedented rise for different fuel configurations in near field region strongly indicates flaming combustion behavior.

To understand the singularity in transitional behavior, next we look at the images of the respective configurations. Figure 6 shows the pictorial views of the different configurations in near field zone at $0.50 \mathrm{~cm}$. Looking at the pictures, one can note the existence of transitional combustion verifying the magnifying rise of regression rate. In retrospect of this, the interaction dynamics between the candle flame and the incense $\operatorname{stick}(\mathrm{s})$ can be segregated as (1) interactions with consistent flaming transition (all heat sources and pilot fuel sustain flame), (2) interactions with consistent and parallel flaming-smoldering transition (cannot sustain flame with time), and (3) interactions with enhanced smoldering transition (enhanced smoldering). It is essential to mention that candle flame is common for all the cases. This transitional branching pertains to the number of the external heat sources. As the experimental images reveal, four-fuel configurations exhibit first form of transition, namely, consistent flaming, and are reflected in highest rise in regression rates. Looking at the picture in Figure 6(d), one can note combined bigger flame, while reduced heat source configurations, namely, two or three fuels, can be noted to adhere to the flaming-smoldering transition. Here, combined flame can be noted to present for some time and then transpires to smoldering. Singlefuel configuration represents the third form of transition, namely, smoldering. The smoldering regression rate enhances for pilot fuel being in immediate vicinity of flame. However, the transition from smoldering to flaming is not noticed.

Since the transitional behavior was evident in the near field region and varied with different configurations, this study was carried out to investigate the controlling aspects. Four selected configurations, namely, three, four, six, and eight heat sources, were adapted for the study in the nearby field zone. Figure 7 shows the near field effects of the external heat sources on the regression rate for different configurations. The transition phenomenon is specified with the cases of flaming, smoldering, and flaming-smoldering. Looking at the plot one can note that the regression rates follow a monotonic increasing trend as the separation distance is reduced. At very close separation distance of $0.5 \mathrm{~cm}$, all the listed cases report transition from smoldering to flaming, ranging from short duration to sustained flaming. The external heat source effect is noted with $46 \%$ rise for three-fuel configuration and $414 \%$ rise for four-fuel configurations. With increase in number of heat sources, namely, six-fuel configuration, the regression rate rises by $470 \%$ whereas the regression rate increase drops with eight-fuel configuration ( $330 \%$ rise). An interesting case noted in nearby field is at $1 \mathrm{~cm}$ separation distance. The regression rate increase drops drastically to $12 \%$ rise for three-fuel configuration to $41 \%$ rise for four-fuel configuration and $36 \%$ rise for six-fuel configuration. Eightfuel configuration manifests transitional behavior in the form of $205 \%$ rise in spreading rates. Regression rate for all the cases converges at $2.5 \mathrm{~cm}$ signifying the end of the nearby field region. The spreading rate rises for all cases but extent of rise is different. The rise reflects the enhanced heat transfer to 


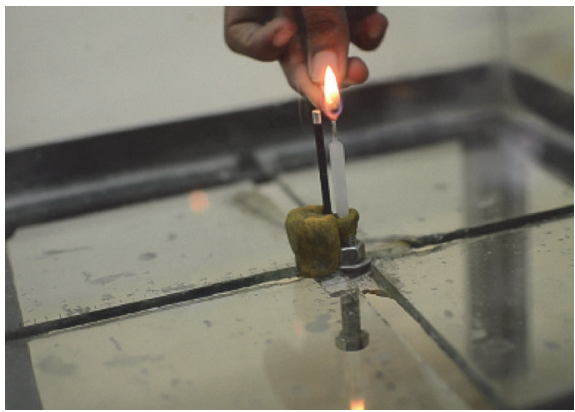

(a)

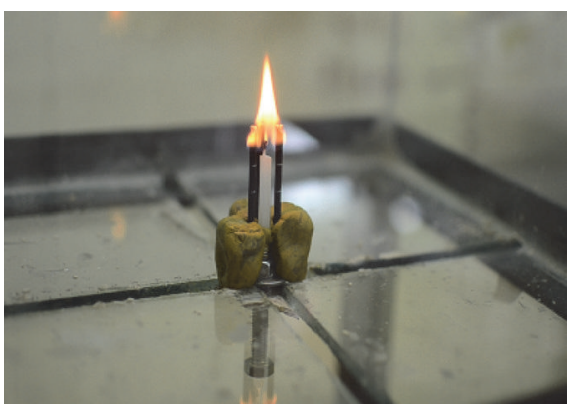

(c)

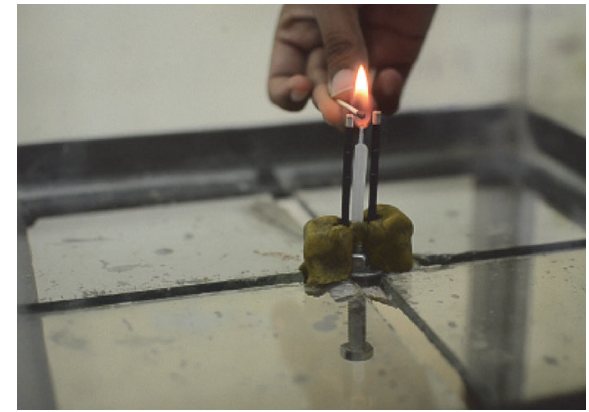

(b)

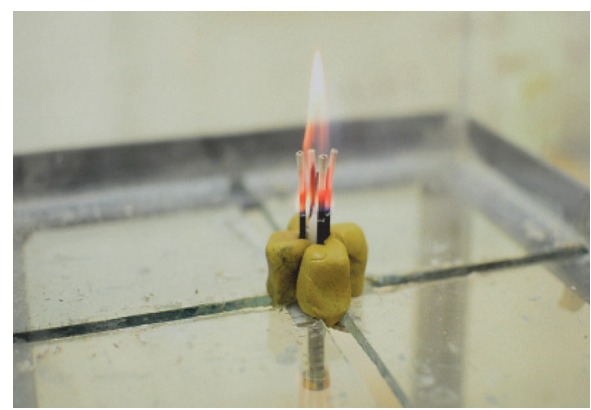

(d)

FIGURE 6: Pictorial view of external heat source (incense sticks) location and number on smoldering combustion at $0.5 \mathrm{~cm}$ : (a) single, (b) two, (c) three, and (d) four incense sticks.

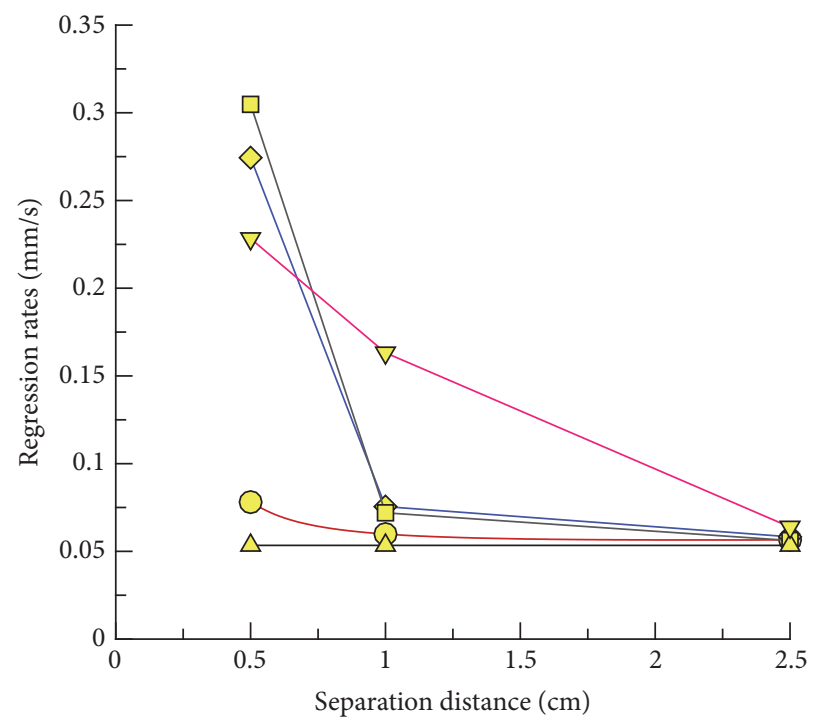

$\neg-$ Without external sources

With candle flame (center)

-o- Three incense sticks

$\checkmark$ Four incense sticks

$\neg-$ Six incense sticks

$\rightarrow-$ Eight incense sticks

FIGURE 7: Nearfield effect of external heat source configurations and separation distance on smoldering. 

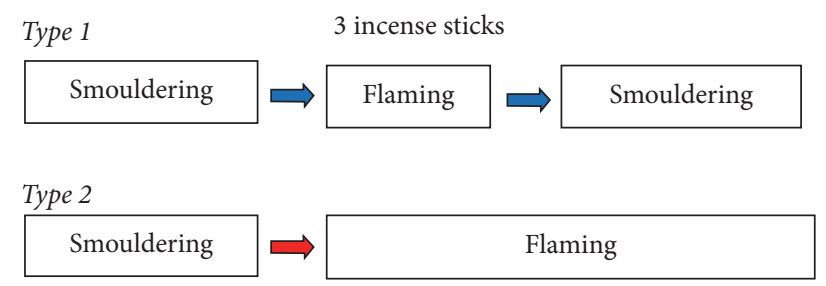

FIGURE 8: Schematic analysis of transition in smoldering combustion for 3 incense sticks.

the unburnt fuel due to higher temperature gradients owing to buoyant convection. The quantitative diverse heat transfer behavior can be attributed to the smoldering transition. The above-mentioned slow combustion behavior can be classified in two cases of transitions: (a) transition with consistent flame propagation and (b) transition with flame-smoldering propagation. Different configurations adhere to any one of the cases and thus the related implications.

Figure 8 depicts the transition observed for distinct case of three and greater than three fuel stick behavior at $0.5 \mathrm{~cm}$. Figure 9 shows the pictorial view of spreading for cases of three-, four-, six-, and eight-fuel configurations at $0.50 \mathrm{~cm}$. Observing the images, we can note that, of threefuel configuration, the induced flaming on the incense sticks was not sustained for the entire measurement length and thus transitioned from smoldering to flaming to smoldering again (type (b)). For the configurations with low regression rates, it is evident as smoldering dominant transition leading to lower spread rates. Also, longer flaming durations seen for more incense sticks increase the spread rates by gargantuan extent representing transition type (a). In these cases, the flames were seen to be sustained for a major part of measurement length primarily because of mutual and collective interaction among the flames (heat source + incense sticks). Mutual and collective interaction refers to the flame-flame interaction, which results in enhanced heat flux arriving at each incense stick resulting in higher regression rates. Because the separation distance $(0.5 \mathrm{~cm})$ is of the order of or even less than that of the flame length scale, the flames appear collectively, that is, unified. Collective interaction causes lower heat losses as the local temperature gradients between flames are eased out and thus heat transfer from flames comes down. For the case of eight incense sticks, the regression rates are a bit lower than four and six incense sticks at $0.5 \mathrm{~cm}$. This is due to the oxygen starvation of the individual flames on account of very less separation. There is increased oxygen demand due to more number of flames, which results in significant deficit and thus lower heat generation by individual flames. It is to be noted that, within nearfield zone, as the separation distance increases, the regression rate drops drastically. An interesting case is at $1 \mathrm{~cm}$ separation distance where, unlike other configurations, eight-fuel configuration demonstrates $205 \%$ rise in regression rate. The reason for this magnificent increase can be attributed to the intermittent flaming (smoldering followed by flaming and then smoldering). This intermittent flaming is seen only for the eight incense sticks case and not for remaining case. Here, we emphasize that a separation distance of $1 \mathrm{~cm}$ is an "intermediate region" for the case of eight incense sticks but more of a "far field" region for other fuel configurations, which supports the fact of intermediate region being a function of the number of incense sticks.

Heat transfer is well known to be dependent upon the directional constrains. Next, we look at the transitional smoldering in the vertical direction. The smoldering phenomenon is expected to be sustained for longer and transition to be faster owing to stronger buoyant convection. Similar to the horizontal case, the vertical separation distance is split into three diverse regions primarily based on type of transition, namely, far field $(>7.5 \mathrm{~cm})$, intermediately spaced $(2.5-$ $7.5 \mathrm{~cm})$, and narrow-spaced $(<2.5 \mathrm{~cm})$ region, respectively. The investigation is carried out for two cases: (a) singlefuel configuration and (b) diametrically opposite placed twin fuel configuration. Figure 10 illustrates the effect of vertical separation distance on the affinity of incense stick configurations on transition to catch fire or to smolder. The effect is noted with respect to the time taken for transition initiation. Experimentation verifies the existence of diverse transitional smoldering in three regions. When placed in the nearby field region, the smoldering-flaming transition is noted for both the cases of single and twin fuel configurations. The incense sticks for both the cases show only flaming or smoldering tendency. Increase in vertical separation distance transits to transitional fire-smoldering region. As the title suggests, in this vertical separation band, the incense stick(s) displays sense of smoldering followed by flaming that is not sustained and transits to smoldering again. In this region, the twin fuel configuration is found to be more sensitive to the influence of buoyant convection. At a selected distance of $5.5 \mathrm{~cm}$, the twin fuel configuration transits to flaming in half the time of single-fuel configuration.

Up next is the far field region where only transitional smoldering is observed to occur with time. This region also marks relative insensitiveness of the fuel configurations for smoldering transition. The vertical separation effect on transitional smoldering is depicted using a single incense stick in Figure 11. The salient aspects are noted at selected time intervals. The incense stick is denoted by the solid black line vertically above the heat source. At time $t_{1}>t_{0}$, the incense stick starts to smolder and eventually starts to burn at time $t_{2}$. The difference $\left(t_{2}-t_{1}\right)$ is expected to vary for most of the practical cases of similar interest. At time $t_{3}$, the central flame bifurcates into two, each one of it seeking the fuel on the respective sides (marked by the arrow direction). As the twin flames propagate away from the heat source, the twin flames start losing the pilot effect provided by the heat source and lose more heat than generation. This unstable condition leads the flame to cease propagating and transition back to smoldering. The same qualitative arguments hold good for the two-fuel case also. Figure 12 highlights the experimentation images for the above-mentioned single-fuel configuration. It is interesting to note that the time for smoldering/flaming is less at $5.5 \mathrm{~cm}$ vertical separation for the two-fuel configuration as one of the two fuels caught fire.

As the experimental simulations were carried out within glass enclosure. It is obligatory to clear the role of enclosure on regression rates. A study was carried out for smoldering 


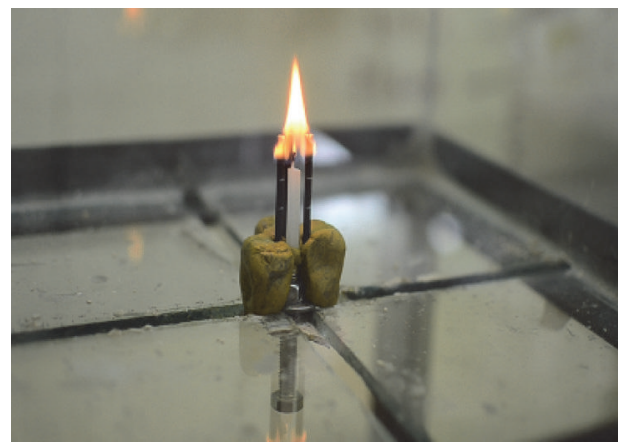

(a)

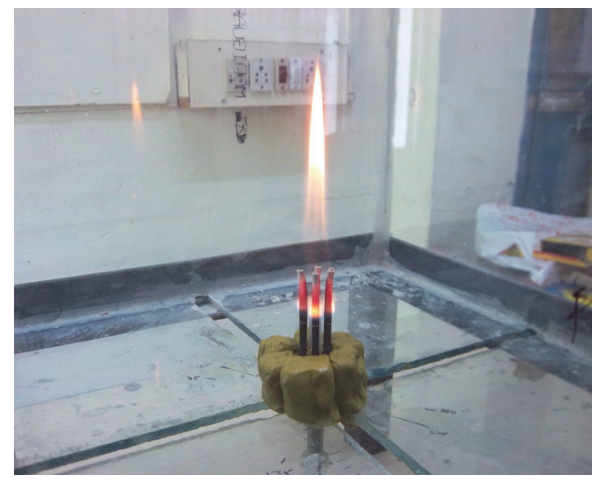

(c)

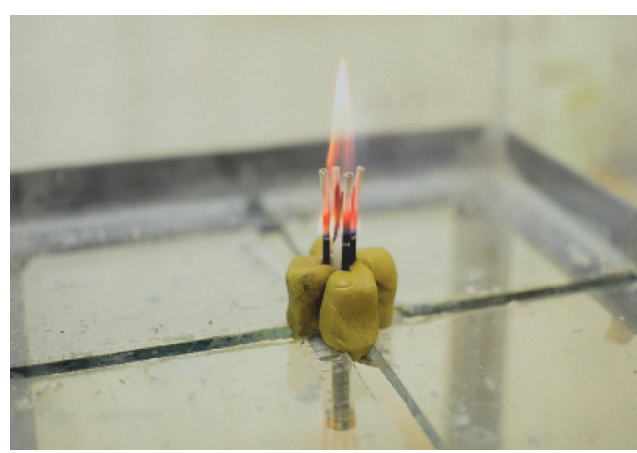

(b)

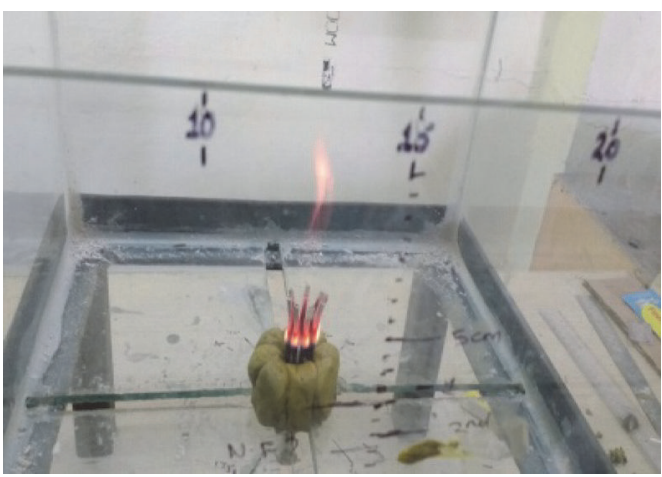

(d)

Figure 9: Pictorial view of transitional smoldering in nearby field $(0.5 \mathrm{~cm})$ : (a) three, (b) four, (c) six, and (d) eight incense sticks, respectively.

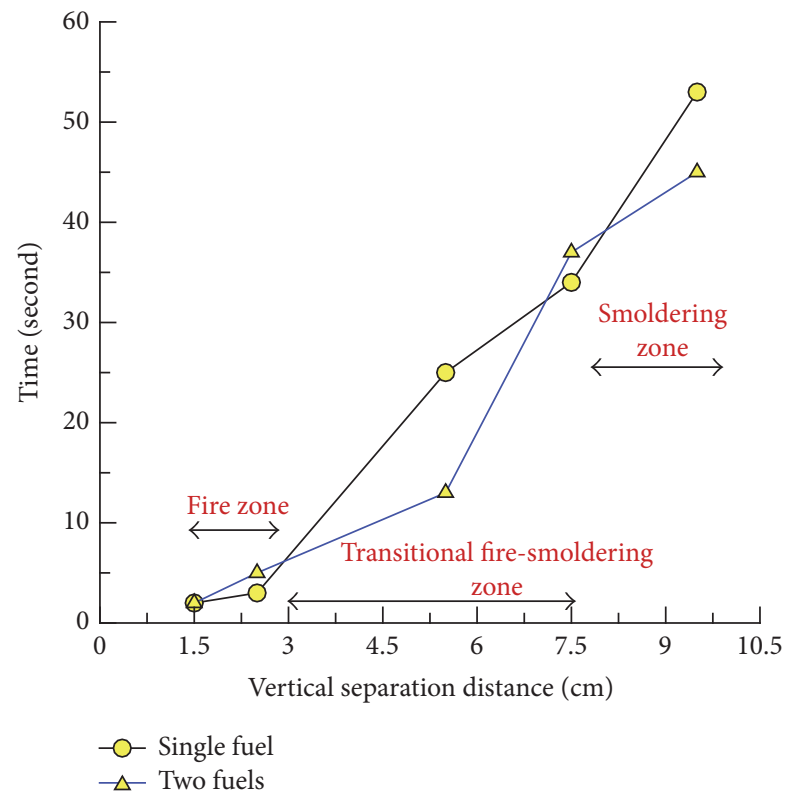

FIGURE 10: Effect of buoyant convection on transitional smoldering.

case of single incense stick with flaming heat source (candle) for cases with and without enclosure. Figure 13 shows the enclosure effect on the regression rate of a single incense stick with separation distance in comparison to the one without

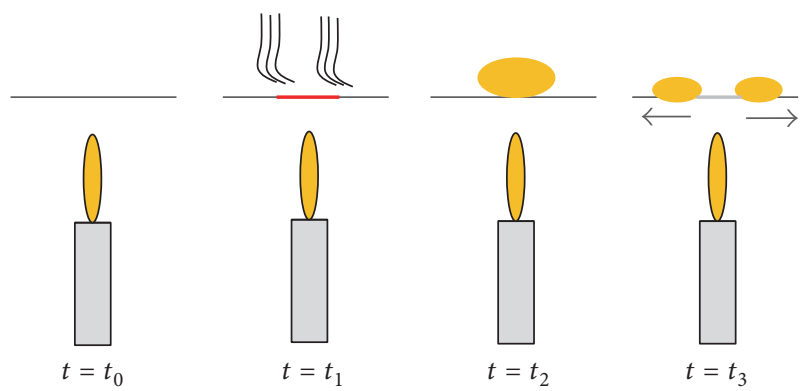

FIGURE 11: Schematic view of incense stick kept vertically at various time instants " $t$ "; $t_{3}>t_{2}>t_{1}>t_{0}$.

enclosure. It was noted that the spread rates do not vary appreciably and lie well within the margins of experimental error. This is expected as the dimensions of the enclosure are large compared to that of any active element (heat source + incense stick) in the system and thus does not appreciably influence any observation significantly. The experimental images are shown in Figure 14.

Fuel placement is well known to affect the regression rates. In order to check the extent of fuel placement/orientation on the regression rates, a study was carried out to measure the regression rate for two orientations which have the incense sticks equidistant from the heat source. Three incense sticks' configuration was selected for 


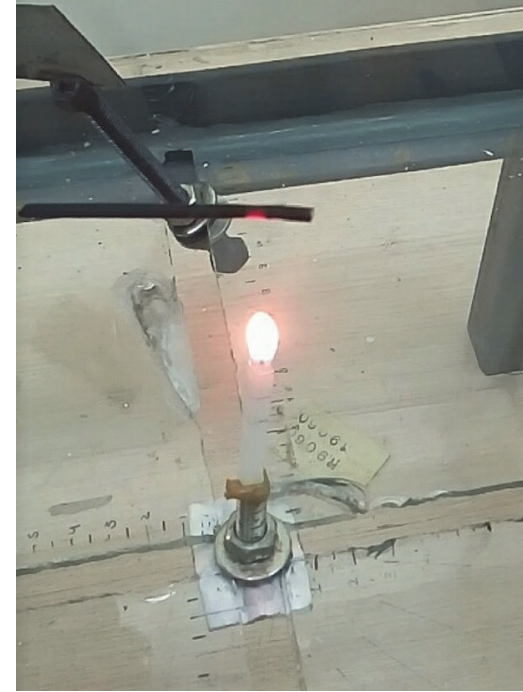

(a)

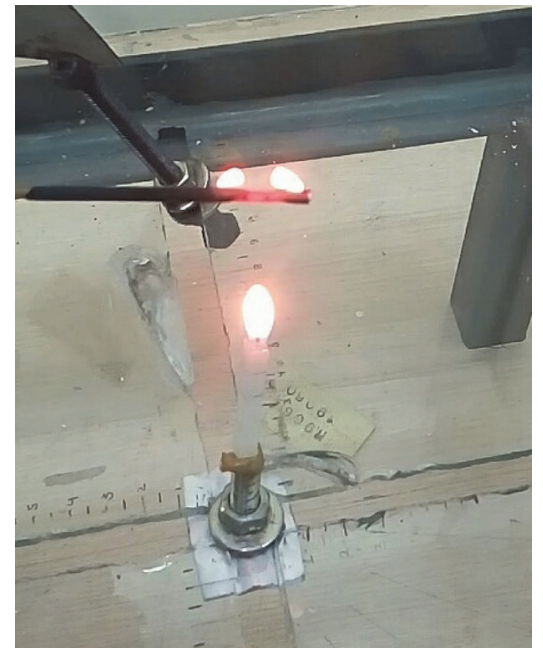

(c)

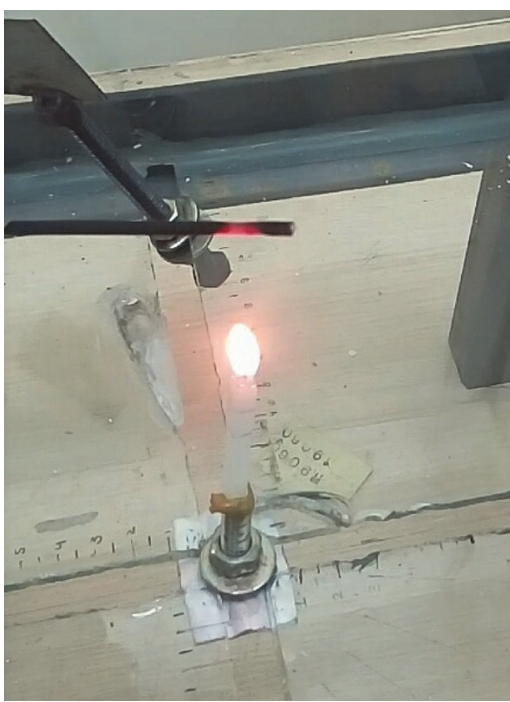

(b)

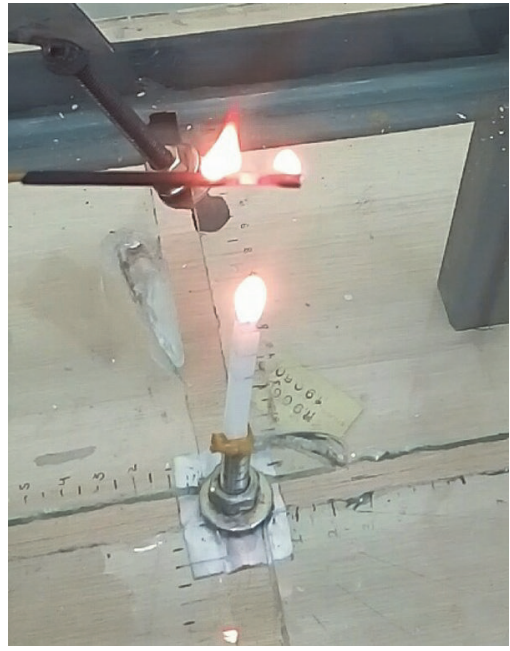

(d)

FIGURE 12: Pictorial view of buoyant convection effect on transitional smoldering.

the cases of symmetrical $\left(120^{\circ}\right.$ separated) "Y orientation" and "T orientation" ( $90^{\circ}$ separated) on the regression rate (please see Figure 15). The regression rate variation with separation distance for "Y orientation" configuration follows trend similar to "T orientation." "Y orientation" configurations at all distances yield lower regression rate except for the farthest distance. Assume that " $x$ " $\mathrm{cm}$ is the distance from heat source to incense sticks for both configurations. The circumferential distance between each incense stick for " $\mathrm{T}$ orientation" configuration is $S=(x * \pi / 2) \mathrm{cm}$, whereas, for "Y orientation," it is $S=(x * 2 \pi / 3) \mathrm{cm}$, which is larger than the symmetrical case separation. This larger spacing causes lower mutual and collective interaction between flames at nearby separation distances, namely, $x=0.5 \mathrm{~cm}$. For larger values of " $x$," lower heat loss from incense stick smoldering to surrounding due to lesser spacing causes the regression rates at $90^{\circ}$ to be higher than that of $120^{\circ}$. Figure 16 shows the experimentation images of three incense sticks' configuration for " $\mathrm{T}$ " orientation and "Y" orientation.

Applicability of the Work. Fire is of many uses but if not controlled is also cause of biggest disasters resulting in loss of resources and mankind and every year huge amount of economical aspect is undertaken to prevent fires, namely, forest fires, compartment fires, building fires, and fires in/on power generating devices, and to understand their behavior under diverse conditions. The work covers wide range of practical, functional, scientific, organizational, and engineering applications. Smoldering and flaming sources are significantly probable in environments of all scales. Once initiated, fire sustains and propagates itself by means of igniting potential fuels which in turn ignite nearby fuels. Fire safety specifies that fire can be detected, prevented, and if possible extinguished. Present work will be extremely 


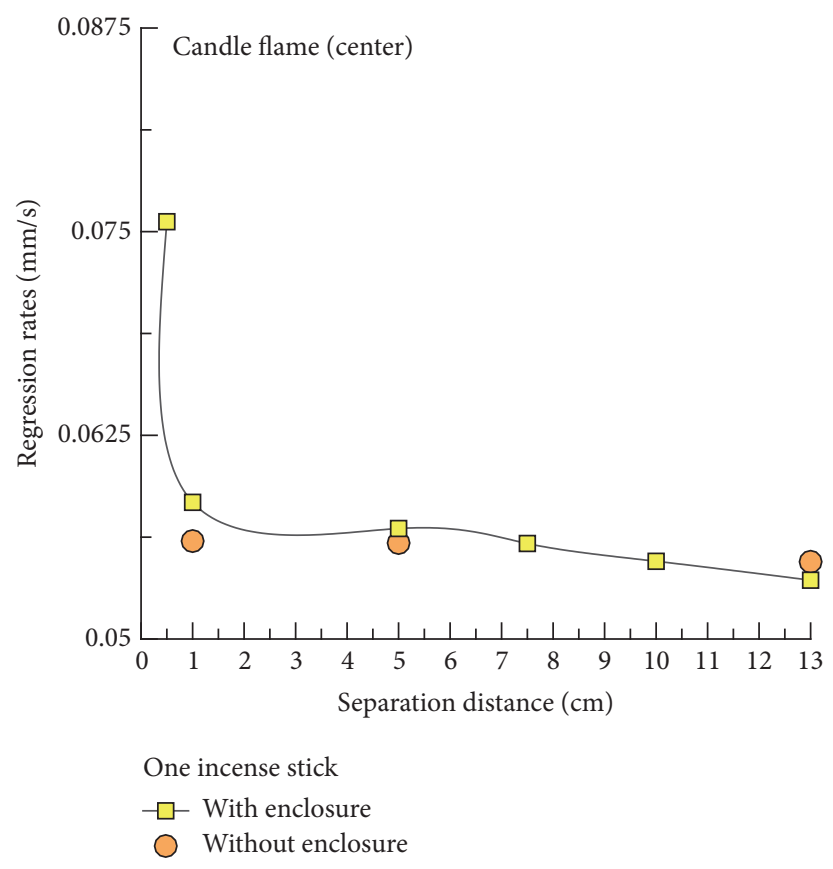

FIGURE 13: Enclosure effects on smoldering combustion.

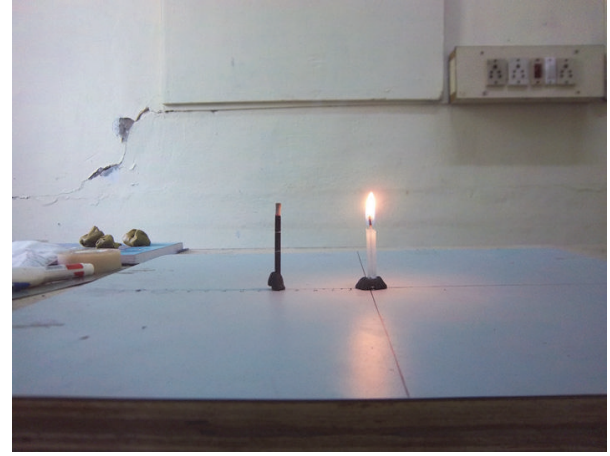

(a)

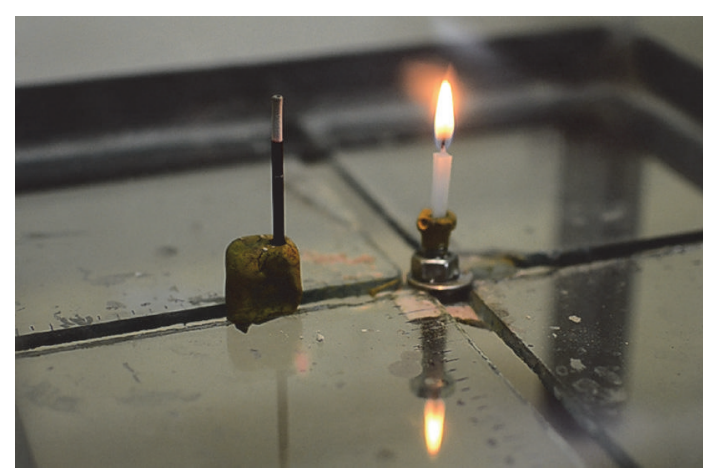

(b)

FIGURE 14: Pictorial view of the enclosure effect on smoldering combustion for single-fuel configuration at $5 \mathrm{~cm}$ : (a) without enclosure; (b) with enclosure.

helpful in bringing necessary awareness regarding fire safety with respect to the transitional smoldering-flaming combustion and coupling between them. In consideration of fire safety, redundant transition to smoldering owing to nearby placement of any external heat source may lead to hazardous threats necessitating proper prevention. It is of paramount important to prevent the smoldering to flaming transition as it increases the damage by multiple folds and reduces necessary prevention control. The losses incurred owing to smoldering to flaming combustion are independent of the occurrence within or without enclosure. The number of heat sources and their placement in the immediate vicinity upsurge damage owing to smolderingflaming transition. However, after a critical number, the effect drops to smoldering only. Small scale and medium scale fires can have influence on the fire propagation by virtue of active interactions with the fire sources in immediate vicinity, whereas, for large scale fires, the dimensions of fire are small compared to the spatial extent and thus can be treated as an isolated system where the interaction is purely between the flaming source and the potential fuel. In the eventuality of a fire accident, potential fuels which are placed higher than the surroundings have much higher potential to be flammable than even fuels that are laterally separated at lesser distance from the flaming source. This key point decides key design aspects of any workspace that have potential fuels invariably.

\section{Conclusions}

An experimental reverse smoldering combustion investigation was carried out to estimate the role of external heat source on smoldering and transitional combustion process. 


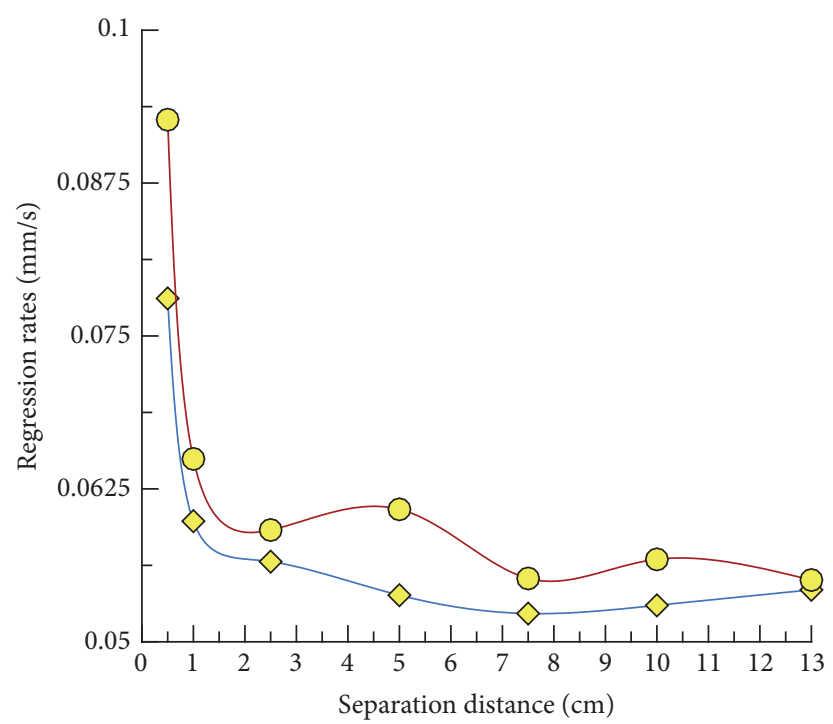

Three incense sticks

Candle flame (center)

$\checkmark$ Y orientation

$-\mathrm{T}$ orientation

FIGURE 15: Symmetry effects on smoldering combustion.

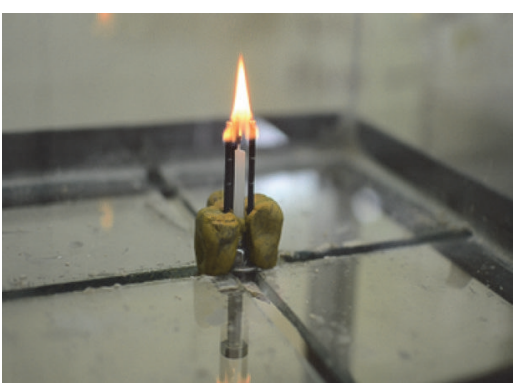

(a)

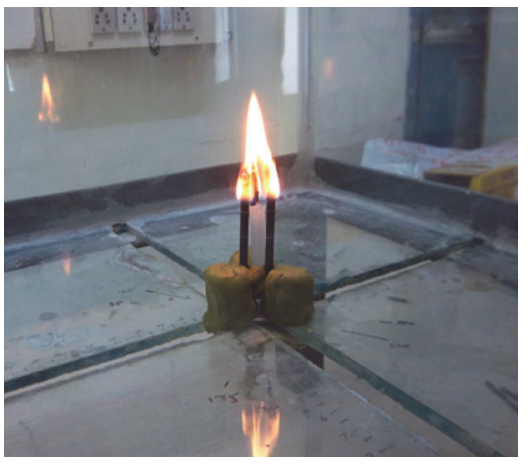

(d)

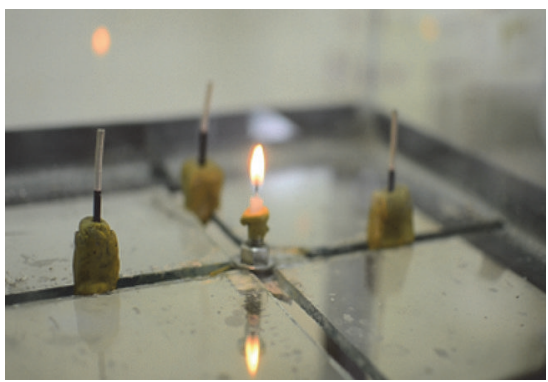

(b)

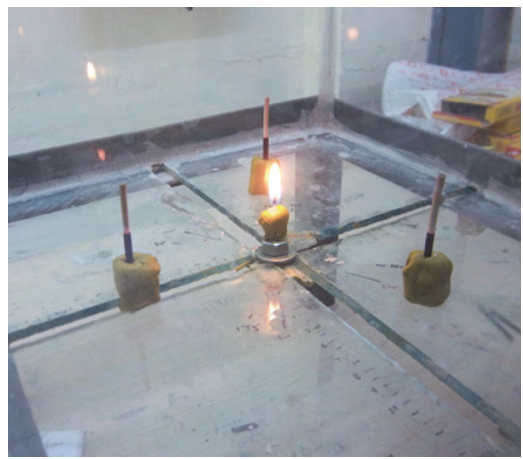

(e)

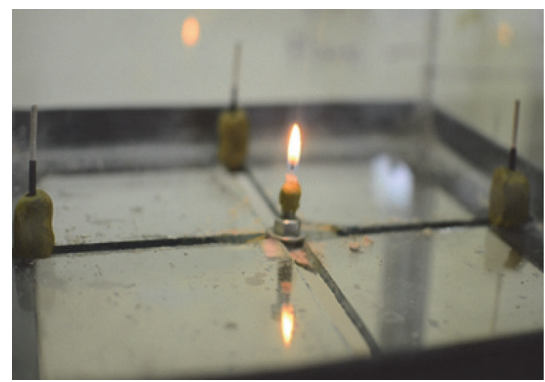

(c)

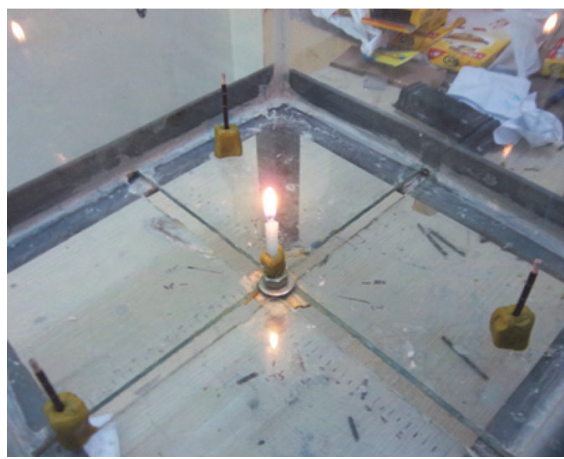

(f)

FIGURE 16: Pictorial view of the three incense sticks' configuration "T" orientation at (a) $0.5 \mathrm{~cm},(\mathrm{~b}) 7.5 \mathrm{~cm}$, and (c) $13 \mathrm{~cm}$ and "Y" orientation at (d) $0.5 \mathrm{~cm}$, (e) $7.5 \mathrm{~cm}$, and (f) $13 \mathrm{~cm}$.

The effect of controlling parameters, separation distance from the flaming source, and the number of incense sticks was evaluated in aid of the pilot fuel regression rate and type of transition. Based on the exploration, the role of controlling parameters in transitional combustion may be concluded as follows:

(1) Separation distance: presence of an external heat source significantly affects smoldering transition. The 
heat source effect rises steadily with reduction in separation distance. In the near field region, all forms of transitional phenomenon occur, namely, (a) only smoldering, (b) smoldering to flaming and vice versa, and (c) only flaming. In upward direction, transitional combustion is aggravated with separation distance being more prone to flaming due to the dominating effect of the convective flow enthalpy. Work marks three distinct transition regions identified by the extent of convective heat transfer.

(2) Number of external heat sources: spreading rate varies substantially with the number of incense sticks principally in the nearby field zone. The combustion transition type is determined by the relative balance between the two effects: (a) increased regression rate due to mutual and collective interaction between the flames; (b) depleted oxidizer concentration due to a large number of flaming incense sticks resulting weaker flames.

(3) Effect of symmetry: different symmetrical placement of external heat sources significantly affects the regression rate and related transition.

(4) Enclosure effect: presence of an enclosure was noted to have no effect on combustion process. The role of enclosure is important to establish as the real systems have dimensions very large compared to the smoldering or flaming heat source.

(5) Validation and repeatability: experimental predictions were validated with the conventional heat transfer theory and established smoldering work and represent repeatability.

\section{Competing Interests}

The authors declare that there is no conflict of interests regarding the publication of this paper.

\section{References}

[1] S. V. Leach, G. Rein, J. L. Ellzey, O. A. Ezekoye, and J. L. Torero, "Kinetic and fuel property effects on forward smoldering combustion," Combustion and Flame, vol. 120, no. 3, pp. 346$358,2000$.

[2] U. Krause and M. Schmidt, "The influence of initial conditions on the propagation of smouldering fires in dust accumulations," Journal of Loss Prevention in the Process Industries, vol. 14, no. 6, pp. 527-532, 2001.

[3] A. Bar-Ilana, O. M. Putzeysa, G. Reina, A. C. Fernandez-Pelloa, and D. L. Urbanb, "Transition from forward smoldering to flaming in small polyurethane foam samples," Experimental Thermal and Fluid Science, vol. 28, pp. 743-751, 2004.

[4] A. P. Aldushin, A. Bayliss, and B. J. Matkowsky, "On the transition from smoldering to flaming," Combustion and Flame, vol. 145, no. 3, pp. 579-606, 2006.

[5] G. Rein, A. C. Fernandez-Pello, and D. L. Urban, "Computational model of forward and opposed smoldering combustion in microgravity," Proceedings of the Combustion Institute, vol. 31, no. 2, pp. 2677-2684, 2007.
[6] A. P. Aldushin, A. Bayliss, and B. J. Matkowsky, "Is there a transition to flaming in reverse smolder waves?" Combustion and Flame, vol. 156, no. 12, pp. 2231-2251, 2009.

[7] G. Rein, "Smoldering combustion phenomena in science and technology," International Review of Chemical Engineering, vol. 1, pp. 3-18, 2009.

[8] A. B. Dodd, C. Lautenberger, and C. Fernandez-Pello, "Computational modeling of smolder combustion and spontaneous transition to flaming," Combustion and Flame, vol. 159, no. 1, pp. 448-461, 2012. 


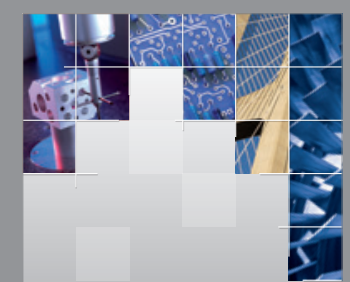

\section{Enfincering}
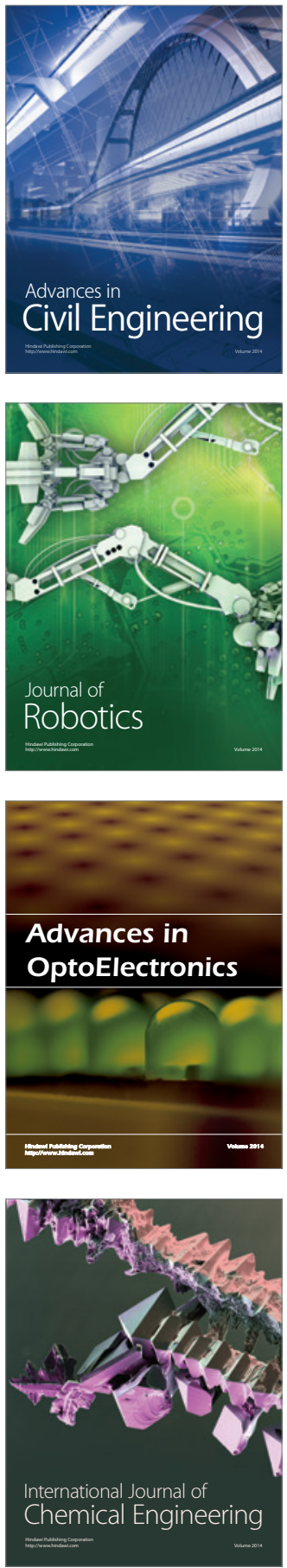

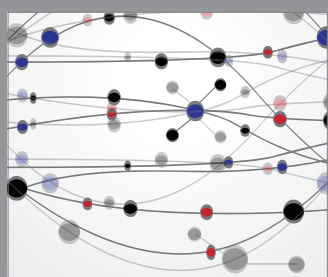

The Scientific World Journal

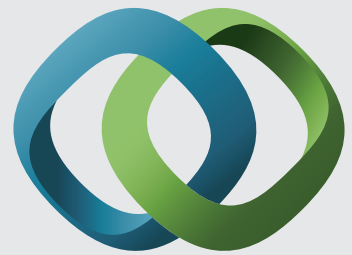

\section{Hindawi}

Submit your manuscripts at

https://www.hindawi.com
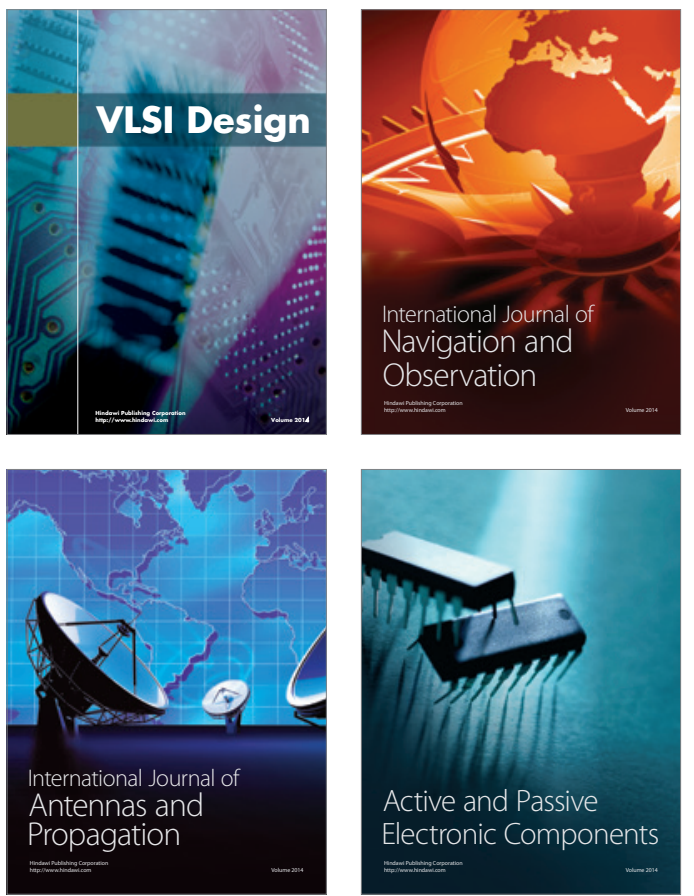
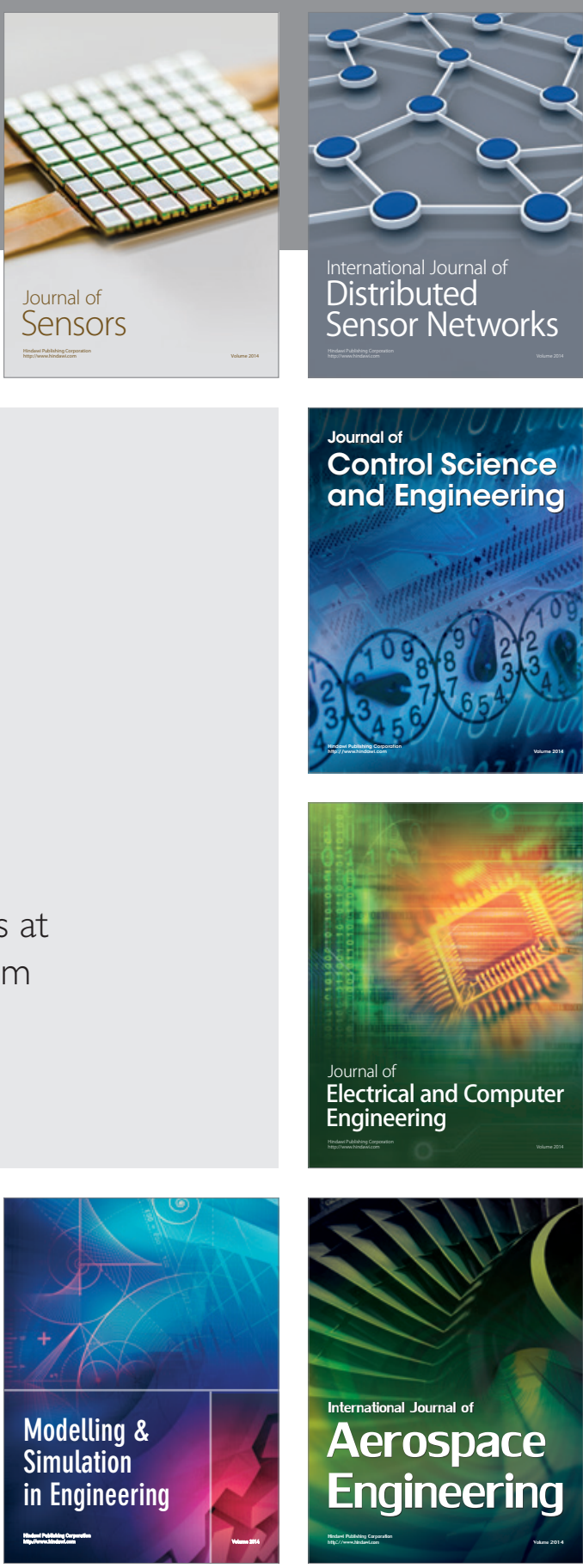

International Journal of

Distributed

Sensor Networks

$-$

Joumal of

Control Science

and Engineering
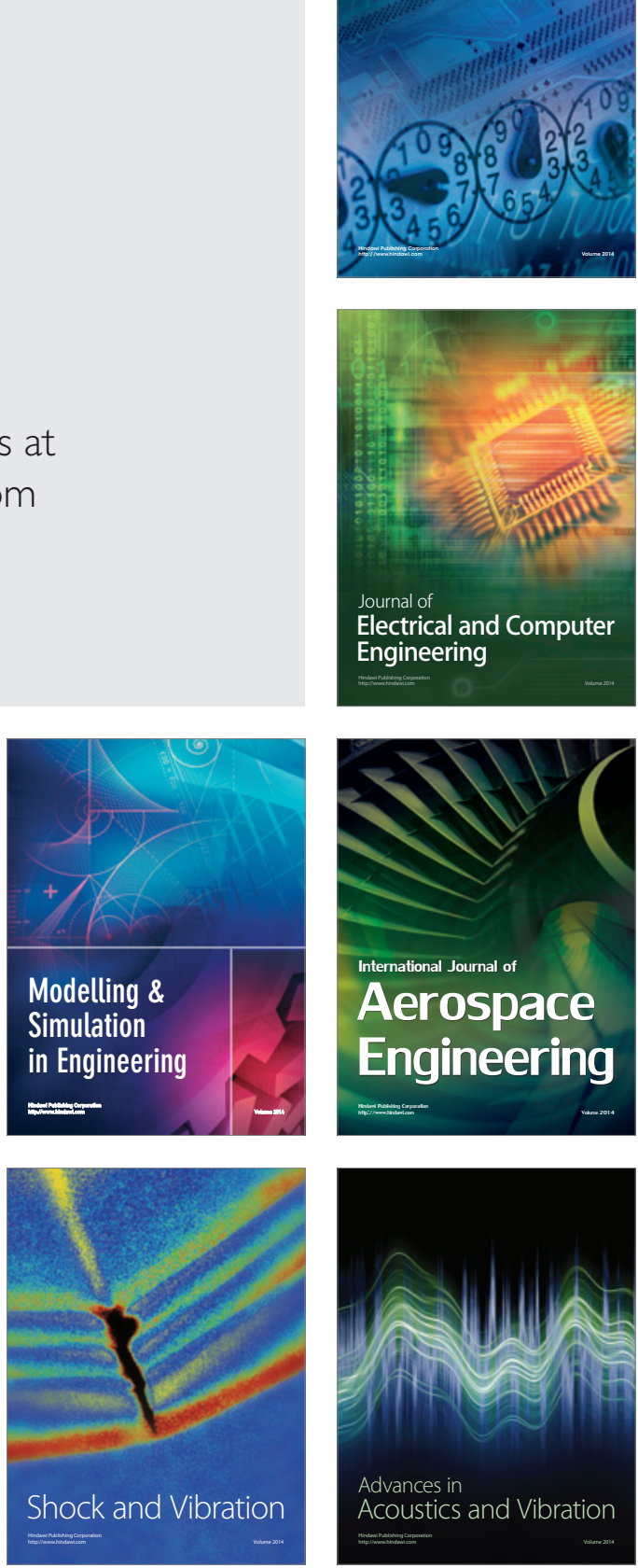